\title{
Patterns of Non-Invasive Ventilation in Amyotrophic Lateral Sclerosis
}

\author{
Nevena Markovic, Marcus Povitz, Joanne Smith, David Leasa, \\ Christen Shoesmith, Teneille E. Gofton
}

\begin{abstract}
Background: Non-invasive ventilation (NIV) improves quality of life and survival in patients with amyotrophic lateral sclerosis (ALS) and respiratory symptoms. Little is known about the patterns of NIV use over time and the impact of NIV on end-of-life decision-making in ALS. Objective: This study assessed the pattern of NIV use over the course of the disease and the timing of end-of-life discussions in people living with ALS. Method: A retrospective single-center cohort study was performed at London Health Sciences Centre. Daily NIV duration of use was evaluated at 3-month intervals. The timing of diagnosis, NIV initiation, discussions relating to do-not-attempt-resuscitation (DNAR) and death were examined. Results: In total, 48 patients were included in the analysis. Duration of NIV use increased over time, and tolerance to NIV was observed to be better than expected in patients with bulbar-onset ALS. There was a high degree of variability in the timing of end-of-life discussions in patients with ALS (356 \pm 451 days from diagnosis). In this cohort, there was a strong association between the timing of discussions regarding code status and establishment of a DNAR order $\left(r^{2}=0.93\right)$. Conclusion: This retrospective cohort study suggests that the use of NIV in ALS increases over time and that there remains a great deal of variability in the timing of end-of-life discussions in people living with ALS. Future prospective studies exploring the use NIV over the disease trajectory and how NIV affects end-of-life decision-making in people with ALS are needed.
\end{abstract}

RÉSUMÉ: Caractéristiques de l'utilisation de la ventilation non-invasive dans des cas de sclérose latérale amyotrophique. Contexte: La ventilation non-invasive (VNI) améliore la qualité de vie et la durée de vie de patients atteints de sclérose latérale amyotrophique (SLA) ainsi que les symptômes respiratoires qui lui sont associés. On connaît toutefois peu de choses quant aux caractéristiques de l'utilisation de la VNI au fil du temps et à son impact en ce qui regarde les décisions prises en fin de vie lorsqu'il est question de la SLA. Objectifs: Cette étude a cherché à évaluer les caractéristiques d'utilisation de la VNI au fur et à mesure de la progression de la SLA et le moment choisi pour aborder la question de la fin de vie dans les cas de patients atteints de cette maladie. Méthodes: Une étude de cohorte rétrospective a été menée dans un seul établissement de santé, à savoir le Centre des sciences de la santé de London. Le temps d'utilisation de la VNI a été évalué tous les trois mois. D'autres aspects ont également été examinés: le moment où un diagnostic de SLA a été posé ; où l'on a commencé à utiliser la VNI ; et où des discussions portant sur la non-réanimation et l'éventualité d'un décès ont été initiées. Résultats: Au total, 48 patients ont été inclus dans le cadre de notre analyse. Si le temps d'utilisation de la VNI a augmenté au fil du temps, on a aussi remarqué, chez des patients atteints dès le début de la forme bulbaire de la SLA, une tolérance meilleure que ce qui était escompté. Un fort degré de variabilité a été noté quant au moment choisi pour initier des discussions portant sur la fin de vie (356 + /- 451 jours à partir d'un diagnostic). Dans cette cohorte, on a pu établir une forte association entre le moment choisi pour initier des discussions portant sur les interventions en cas d'arrêt cardiaque ou respiratoire et l'inscription d'une ordonnance de non-réanimation $\left(\mathrm{r}^{2}=0,93\right)$. Conclusions: Cette étude de cohorte rétrospective suggère donc que l'utilisation de la VNI dans le cas de la SLA augmente au fil du temps. Elle suggère également qu'il subsiste une variabilité considérable en ce qui a trait aux discussions portant sur la fin de vie de patients atteints de SLA. D'autres études prospectives demeurent néanmoins nécessaires. Elles devront en effet se pencher sur l'utilisation de la VNI au cours de la trajectoire de la maladie et sur ses impacts quant aux décisions prises en fin de vie.

Keywords: Amyotrophic lateral sclerosis, Non-invasive ventilation, End-of-life care

doi:10.1017/cjn.2018.25

Can J Neurol Sci. 2018; 45: 445-450

\section{INTRODUCTION}

Assisted ventilation is an important supportive modality available for respiratory symptoms in amyotrophic lateral sclerosis (ALS). Non-invasive ventilation (NIV) uses a face or nasal mask and volume-cycled or bi-level pressure-limited ventilation to provide intermittent positive pressure to decrease the work of breathing. ${ }^{1}$ The use of NIV has been shown to improve both quality of life and survival in patients with ALS and respiratory symptoms. ${ }^{1-5}$ However, few studies address the extent to which patients use NIV throughout the course of the day over time and how the total daily use of NIV may affect
From the Department of Clinical Neurological Sciences, Western University, London, Ontario, Canada (NM, CS); Departments of Medicine and of Epidemiology and Biostatistics, Western University, London, Ontario, Canada (MP); Department of Respiratory Therapy, Western University, London, Ontario, Canada (JS); Department of Medicine, Division of Critical Care and Respirology, Western University, London, Ontario, Canada (DL); Department of Clinical Neurological Sciences and Critical Care Western, Western University, London, Ontario, Canada (TEG).

Received October 11, 2017. Final Revisions Submitted January 20, 2018. Date OF ACCEPTENCE FEBRUARY 25, 2018.

Correspondence to: Teneille E. Gofton, Department of Clinical Neurological Sciences and Critical Care Western, Western University, University Hospital, 339 Windermere Rd, London, ON, Canada N6A 5A5. Email: teneille.gofton@lhsc.on.ca 
decision-making at the end of life. ${ }^{6,7}$ Advance care planning and end-of-life decision-making are important elements in the management of ALS. ${ }^{8-10}$ Understanding how NIV use changes throughout the disease trajectory will help guide patients and families in decisions regarding end of life, as well as the timing of end-of-life discussions. It will also assist physicians with optimizing timing for broaching these discussions. Few prospective observational or large retrospective studies assess the daily use of NIV over time in ALS. ${ }^{11}$

The aim of this study was to assess the pattern of NIV use over time in people living with ALS and to discuss the possible impacts of NIV on palliative care in ALS. A retrospective cohort study was performed in order to describe the pattern of use of NIV and to report on end-of-life discussions.

\section{MeTHODS}

\section{Study Design and Setting}

We conducted a retrospective cohort study of patients with ALS using NIV between January 2011 and December 2014 who attended the Multidisciplinary Motor Neuron Diseases Clinic at the London Health Sciences Centre (LHSC; London, Ontario, Canada). LHSC is a tertiary-care referral center (catchment area two million) with a specialist (neurologist and respirologist) multidisciplinary motor neuron disease clinic. The study was approved by the Health Sciences Research Ethics Board at Western University. The requirement for written informed consent was waived because of the retrospective nature of the study and because all included patients were deceased.

\section{Patients}

The diagnosis of ALS was confirmed by a neurologist (CS), and all patients were followed up at $\sim 3$-month intervals from the time of diagnosis of ALS until the time of death. Only ALS patients prescribed NIV were included in the analysis.

\section{Exposure}

Non-invasive ventilation was initiated in an outpatient setting when patients described one "at-risk" respiratory symptom (e.g., orthopnea, excessive daytime sleepiness, morning headache) or one "at-risk" pulmonary function abnormality (e.g., sitting forced vital capacity $[\mathrm{FVC}]<70 \%$ predicted, supine FVC drops $>20 \%$, daytime $\mathrm{pCO}_{2}>45 \mathrm{mmHg}$, maximum inspiratory pressure less negative than $-40 \mathrm{~cm} \mathrm{H}_{2} \mathrm{O}$ ) or nocturnal hypoxemia. Noninvasive ventilation was implemented using with a bi-level pressure ventilator in spontaneous-timed mode with an oronasal mask interface.

\section{Outcome}

During each clinic visit, neurologic and respiratory symptoms were documented in the patient's chart along with discussions surrounding end-of-life and resuscitation preferences. Data were downloaded from the bi-level device and reviewed for duration of use and for effectiveness of the ventilator prescription to relieve symptoms. Data were documented within a ventilator database from the device that the patient brought to clinic. If a patient had more than one device, which was not brought to clinic visits, then the usage data for the alternate devices were not accessible.

\section{Variables and Data Sources}

Demographics (gender, age at diagnosis, region of symptom onset, presence of cognitive symptoms, time from symptom onset to diagnosis and time from diagnosis to death) and comorbidities were determined from chart analysis. Baseline lung function, ventilator settings, arterial blood gas values and percentof-predicted FVC at the time of NIV initiation, time from diagnosis to NIV initiation, time from NIV initiation to death, duration of daily NIV use over time and duration of nocturnal NIV use (both median and mean) were recorded prospectively for all patients in a clinical electronic ventilator database (Microsoft Excel 2008) at each clinic visit. Timing of radiologically inserted gastrostomy (RIG), the preferred procedure for feeding support at our center (note: percutaneous endoscopic gastrostomy tubes were not used in this cohort), was recorded from the patient chart. Other variables of interest included discussions regarding placement of a RIG, the timing of first end-of-life discussion and timing of do-not-attempt resuscitation (DNAR) order. All data were abstracted retrospectively from patient charts and the ventilator database.

\section{Statistical Analysis}

Means, standard deviations and ranges were determined for baseline characteristics. Proportions and their 95\% confidence intervals were calculated using the Clopper-Pearson method. We assessed for an association between average NIV use and longterm survival on NIV using linear regression. We assessed the association between time of first goals of care discussion and establishment of a DNAR order using linear regression.

\section{Results}

All patients (50) having initiated NIV and who subsequently died within the study period (2011-2014) were included. Two patients were excluded because of an incomplete data set, leaving 48 patients in total for the analysis (mean age 62 years). Regions of symptom onset were lower extremity (21), bulbar (16), upper extremity (10) and diaphragm (1). After initiation of NIV, mean survival was 10.0 [9.92] months (range 0-36.8 months). Detailed demographic information describing the study cohort is outlined in Table 1.

Out of 48 patients, six were noted to have an unusually long disease trajectory. These patients were considered outliers because their disease trajectory varied a great deal from the remainder of the group. Variability in disease trajectory is well recognized in ALS; therefore, outliers are to be expected ${ }^{12}$ (up to $20 \%$ live $>5$ years from the time of diagnosis). Data points $>2$ SD from the mean were noted, and the statistical analysis was performed both with the entire group of patients and with the outliers excluded.

\section{Use of Non-Invasive Ventilation Over Time}

In the first 3 months after initiation of NIV, 16 patients used NIV nocturnally for $<4$ hour per day, 10 patients used NIV for 4-8 hours per day and 6 patients used NIV for $>8$ hours per day (nine died before 3 months, and seven had no data available). The $\mathrm{pCO}_{2}$ in patients using $>4$ hours per day $(48.6[7.4] \mathrm{mmHg})$ from the initiation of NIV was significantly greater than those using NIV $<4$ hours per day $(43.1[4.6] \mathrm{mmHg}, p<0.05)$. There was no significant difference between these two groups with respect to age or FVC at time of referral for NIV. There were an equal number of patients (8) 
Table 1: Demographic information for the retrospective cohort of patients with amyotrophic lateral sclerosis using non-invasive ventilation

\begin{tabular}{|c|c|}
\hline Demographic variable & $n=48$ \\
\hline Age (years) & 31-86 (mean 62) \\
\hline \multicolumn{2}{|l|}{ Gender } \\
\hline Male & 24 \\
\hline Female & 24 \\
\hline \multicolumn{2}{|l|}{ Region of symptom onset } \\
\hline Lower extremity & 21 \\
\hline Bulbar & 16 \\
\hline Upper extremity & 10 \\
\hline Diaphragm & 1 \\
\hline Time from symptom onset to diagnosis of ALS (days \pm SD) & 29-2281 (mean $458[412])$ \\
\hline Time from diagnosis of ALS to death (days \pm SD) & $33-2679$ (mean $614[563])$ \\
\hline Time from diagnosis of ALS to initiation of NIV (days \pm SD) & $2-2129($ mean $312[407])$ \\
\hline $\mathrm{CO}_{2}$ at time of NIV initiation $(\mathrm{mmHg} \pm \mathrm{SD})$ by capillary gas & $34-66($ mean $44.8[6.2])$ \\
\hline FVC at time of NIV initiation ( $\%$ predicted \pm SD) & $25-88($ mean $57[15])$ \\
\hline Patients with DNAR order at any time & 40 \\
\hline \multicolumn{2}{|l|}{ Presence of cognitive symptoms } \\
\hline Yes & 6 \\
\hline No & 42 \\
\hline \multicolumn{2}{|l|}{ Radiologically inserted gastrostomy } \\
\hline Yes & 23 \\
\hline No & 25 \\
\hline
\end{tabular}

ALS = amyotrophic lateral sclerosis; DNAR = do not attempt resuscitation; FVC = forced vital capacity; NIV = non-invasive ventilation

in both groups with bulbar-onset ALS. After 6 months, four patients used NIV nocturnally for $<4$ hours per day, five patients used NIV for 4-8 hours per day and 12 patients used NIV for $>8$ hour per day (17 died before 6 months, and 10 had no data available). Figure 1

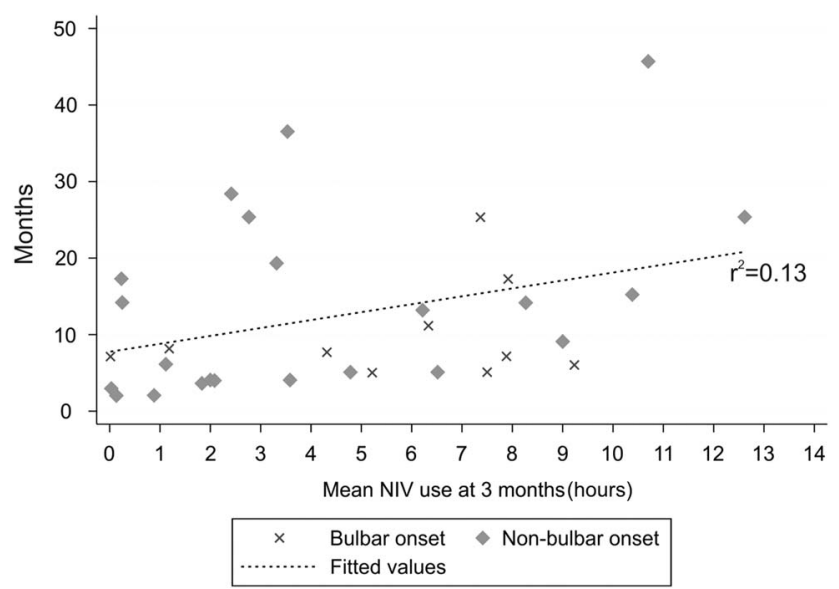

Figure 1: Regression analysis of the daily non-invasive ventilation (NIV) use in hours at 3-month intervals and its relationship to survival $\left(r^{2}=0.13\right)$. Patients with bulbar-onset amyotrophic lateral sclerosis are represented by an $\times$ and patients with other regions of onset are represented by a diamond shape. shows the pattern of NIV use over time. Regression analysis of average daily NIV use at 3 months and survival was $r^{2}=0.13$ (32 data points), and at 6 months it was $r^{2}=0.04$ (21 data points). Patterns of NIV use over time are represented in Table 2. All but three of the bulbar-onset patients tolerated NIV for greater than 4 hours per day over a period of multiple visits (visits at 3-month intervals, detailed data not shown).

\section{End-of-Life Discussions}

Patterns of end-of-life discussions are represented in Figure 2. Overall, 40 patients had a documented DNAR as part of their care plan, $35 \%$ were established before initiation of NIV, whereas the remainder were established after initiation of NIV. The time from diagnosis to first documented discussions regarding code status was 356 [451] days when considering all patients (221 [139] days with outliers excluded). The time from diagnosis of ALS to the establishment of a DNAR order was 427 [475] days (274 [168] days with outliers excluded). The time from diagnosis of ALS to death was 613 [562] days (430 [245] days with outliers excluded). The time from initiation of NIV to establishment of a DNAR order was 96 [266] days (65 [191] days with outliers excluded; Figure 3) and the time from initiation of NIV to death was 301 [298] (260 [226] days with outliers excluded). Eight patients had no documented orders regarding code status within the available charts. There was a strong association between the timing of first 
Table 2: The pattern of non-invasive ventilation (NIV) use at 3-month intervals following initiation

\begin{tabular}{|c|c|c|c|c|c|}
\hline Encounter no. & $\begin{array}{l}\text { Number of surviving } \\
\text { patients/encounter }\end{array}$ & $\begin{array}{l}\text { Number of patients } \\
\text { with NIV data available }\end{array}$ & $\begin{array}{c}<4 \text { hour/day NIV use } \\
(\% \text { patients })\end{array}$ & $\begin{array}{c}\text { 4-8 hour/day NIV use } \\
\text { (\% patients) }\end{array}$ & $\begin{array}{c}>8 \text { hour/day NIV use } \\
\text { (\% patients) }\end{array}$ \\
\hline 1 (0-3 months) & 39 & 32 & $16(50)$ & $10(31)$ & $6(19)$ \\
\hline 2 (4-6 months) & 31 & 21 & $4(19)$ & $5(24)$ & $12(57)$ \\
\hline 3 (7-9 months) & 12 & 12 & $2(17)$ & $2(17)$ & $8(67)$ \\
\hline 4 (10-12 months) & 10 & 10 & $1(10)$ & $3(30)$ & $6(60)$ \\
\hline 5 (13-15 months) & 7 & 7 & - & $2(29)$ & $5(71)$ \\
\hline 6 (16-18 months) & 3 & 3 & - & - & $3(100)$ \\
\hline 7 (19-21 months) & 3 & 3 & - & - & $3(100)$ \\
\hline 8 (22-24 months) & 1 & 1 & - & - & $1(100)$ \\
\hline 9 (25-27 months) & 1 & 1 & - & - & $1(100)$ \\
\hline 10 (28-30 months) & 1 & 1 & - & - & $1(100)$ \\
\hline 11 (31-33 months) & 1 & 1 & - & - & $1(100)$ \\
\hline
\end{tabular}

Each encounter occurred at 3-month intervals after initiation of NIV. Data are included only for patients from whom a full data set was available at each visit

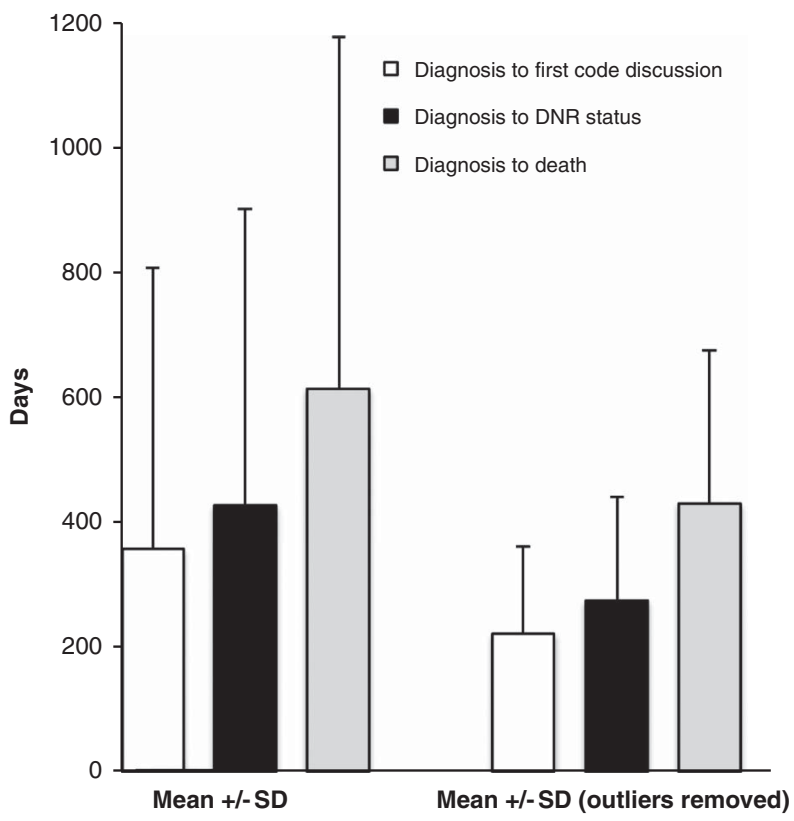

Figure 2: The time from diagnosis of amyotrophic lateral sclerosis to the first documented code status discussion, to establishment of a donot-attempt-resuscitation order and to death. Data are presented as a mean $\pm S D$. The data are presented with (left) and without outliers (right; outliers $=$ data points $>2 S D$ from the mean).

documented discussion regarding code status and establishment of a DNAR order (Figure $3 \mathrm{~A} ; r^{2}=0.93$ ) and between the time to the initiation of NIV and establishment of a DNAR order (Figure 3B; $r^{2}=0.89$ ).

\section{DISCUSSION}

This study suggests the following: (1) NIV use increases over time in most patients with ALS; (2) NIV may be tolerated in patients with bulbar-onset ALS; (3) there remains a high degree of variability in the timing of end-of-life discussions in patients with ALS; and (4) in this cohort, there is a strong association between the timing of discussions regarding code status and establishment of a DNAR order.
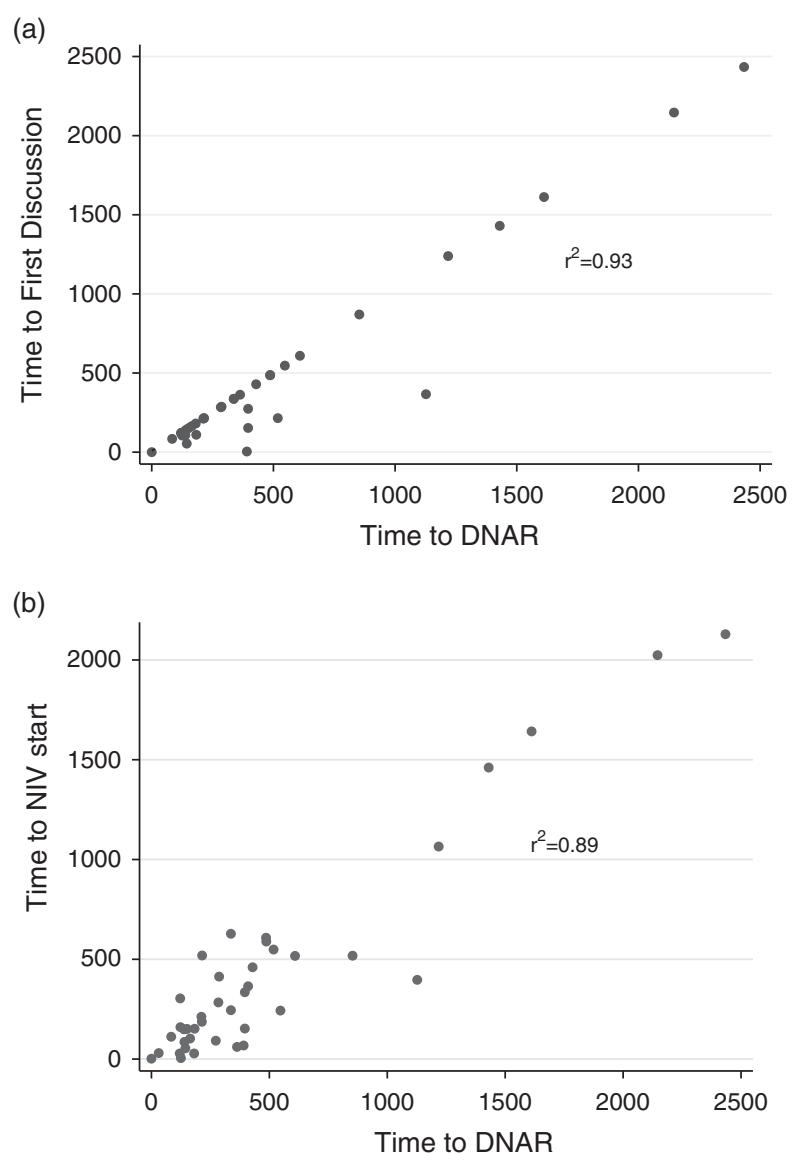

Figure 3: (A) The timing of first documented code discussion versus the timing of a first documented do-not-attempt-resuscitation (DNAR) order. There is a strong association with $r^{2}=0.93$. (B) The timing of initiation of non-invasive ventilation (NIV) versus the timing of a first documented DNAR order, $r^{2}=0.89$.

Within the first 3 months of NIV initiation, more patients were already using NIV for longer than 4 hours and by 6 months most patients were using NIV for more than 8 hours. This demonstrates 
the natural progression of respiratory dysfunction as the disease advances and offers preliminary objective information for patients and families regarding NIV use over time. ${ }^{11}$ Increased use of NIV over time is expected, but not well documented in the literature. Non-invasive ventilation remains the most important supportive modality in ALS and has been shown to improve median survival time in patients with respiratory symptoms more than any other treatment to date. ${ }^{13,14} \mathrm{~A}$ randomized control trial by Bourke et $\mathrm{al}^{1}$ in 2006 found that this survival benefit was in patients without severe bulbar symptoms. A more recent and larger retrospective study of 929 patients found the opposite result where patients with bulbar-onset ALS had the greatest survival benefit. ${ }^{15}$ Within our cohort, one-third of patients had bulbar-onset disease in keeping with the more recent literature suggesting that bulbar-onset patients may tolerate and benefit from NIV. ${ }^{15}$

There remains poor consensus on optimal timing for endof-life discussions in ALS. ${ }^{16}$ There is consensus that advance care planning discussions should occur, but there is little evidence to support the timing of such discussions. ${ }^{8-10}$ Within our cohort, there was a strong association between the timing of first documented discussion regarding code status and establishment of a DNAR order. It is difficult to understand whether this relationship exists because the physician was good at gauging patient's readiness to address the topic or that patients are prepared to talk about endof-life decisions from even earlier in the course of the disease. In another retrospective study of 43 patients with ALS, of the patients who chose a DNAR status, $83 \%$ made the decision at the initial clinic visit and it seemed to be independent of their level of respiratory insufficiency. ${ }^{17}$ In our study, 40 patients had a documented DNAR as part of their care plan, $35 \%$ were established before initiation of NIV, whereas the remainder were established after initiation of NIV. Advance care planning, including discussion regarding code status, should take place early in the disease trajectory. Consideration of NIV in ALS should be a trigger for palliative care discussions if they have not already taken place. ${ }^{16}$

Limitations to our study relate to the retrospective nature of data collection. Although all patients used NIV nocturnally, a small number of patients $(<8)$ also used NIV during the day as their disease advanced. The ventilator database contains information primarily from nocturnal NIV because these patients had a separate daytime machine and did not bring it to clinic visits. Therefore, we did not have accurate data on daytime use in these eight patients, which probably resulted in an underestimation of their daily usage of NIV. Other contributing factors to duration of use such as intolerance to the machine or effects on quality of life were not addressed in this study. Last, discussions regarding resuscitation status and end-of-life care may have occurred at earlier clinic visits and not necessarily documented if no specific decision had been made.

This study was performed at a single academic center in Canada. However, the demographics of this cohort are consistent with the current literature (e.g., age, gender distribution, region of onset). This suggests that despite being a single-centered retrospective study, the results may be generalizable to greater populations of people living with ALS.

In conclusion, this retrospective cohort study suggests that NIV use in ALS increases over time and provides objective number of hours of NIV use that can be informative to patients and families when starting NIV. It also shows that there remains a great deal of variability in the timing of end-of-life discussions in people living with ALS. Although this study remains relatively small and retrospective in nature, it serves as the groundwork for the design and development of future prospective studies exploring the use of NIV over the disease trajectory and how NIV affects end-of-life decision-making in people with ALS.

\section{FUNDING}

MP has received salary support from the Academic Medical Organization of Southwestern Ontario. TEG has received research support from the Lawson Health Research Institute, the St. Joseph's Health Care Foundation and the Academic Medical Organization of Southwestern Ontario and has received compensation from Medtronic and SAGE Therapeutics for unrelated clinical research.

\section{DisClosures}

CS has participated as a site investigator in clinical trials sponsored by Cytokinetics and AB Science. NM, MP, JS, and TEG have no conflicts of interest to declare.

\section{Statement of Authorship}

Drs. Gofton, Shoesmith, Povitz, and Leasa participated in the study design. Dr. Markovic and Ms. Smith participated in data abstraction. All authors participated in the data analysis, data interpretation, drafting and editing of the final manuscript.

\section{REFERENCES}

1. Bourke SC, Tomlinson M, Williams TL, Bullock RE, Shaw PJ, Gibson GJ. Effects of non-invasive ventilation on survival and quality of life in patients with amyotrophic lateral sclerosis: a randomised controlled trial. Lancet Neurol. 2006;5:140-7.

2. Hein H, Schucher B, Magnussen H. Intermittent assisted ventilation in neuromuscular diseases: course and quality of life. Pneumologie. 1999;53(Suppl 2):S89-90.

3. Lyall RA, Donaldson N, Fleming T, et al. A prospective study of quality of life in ALS patients treated with noninvasive ventilation. Neurology. 2001;57:153-6.

4. Aboussouan LS, Khan SU, Banerjee M, Arroliga AC, Mitsumoto H. Objective measures of the efficacy of noninvasive positivepressure ventilation in amyotrophic lateral sclerosis. Muscle Nerve. 2001;24:403-9.

5. Bourke SC, Bullock RE, Williams TL, Shaw PJ, Gibson GJ. Noninvasive ventilation in ALS: indications and effect on quality of life. Neurology. 2003;61:171-7.

6. Kettemann D, Funke A, Maier A, et al. Clinical characteristics and course of dying in patients with amyotrophic lateral sclerosis withdrawing from long-term ventilation. Amyotroph Lateral Scler Frontotemporal Degener. 2017;18:53-9.

7. Meyer T, Dullinger JS, Munch C, et al. Elective termination of respiratory therapy in amyotrophic lateral sclerosis. Nervenarzt. 2008;79:684-90.

8. Connolly S, Galvin M, Hardiman O. End-of-life management in patients with amyotrophic lateral sclerosis. Lancet Neurol. 2015;14:435-42.

9. Danel-Brunaud V, Touzet L, Chevalier L, et al. Ethical considerations and palliative care in patients with amyotrophic lateral sclerosis: a review. Rev Neurol (Paris). 2017;173:300-7.

10. Oliver DJ, Campbell C, O'Brien T, et al. Medication in the last days of life for motor neuron disease/amyotrophic lateral sclerosis. Amyotroph Lateral Scler. 2010;11:562-4.

11. Hazenberg A, Kerstjens HA, Prins SC, Vermeulen KM, Wijkstra PJ. Is chronic ventilatory support really effective in patients with amyotrophic lateral sclerosis? J Neurol. 2016;263:2456-61. 
12. del Aguila MA, Longstreth WT Jr, McGuire V, Koepsell TD, van Belle G. Prognosis in amyotrophic lateral sclerosis: a populationbased study. Neurology. 2003;60:813-9.

13. Burkhardt C, Neuwirth C, Sommacal A, Andersen PM, Weber M. Is survival improved by the use of NIV and PEG in amyotrophic lateral sclerosis (ALS)? A post-mortem study of 80 ALS patients. PLoS One. 2017;12:e0177555.

14. Radunovic A, Annane D, Rafiq MK, Mustfa N. Mechanical ventilation for amyotrophic lateral sclerosis/motor neuron disease. Cochrane Database Syst Rev, 2013; CD004427.
15. Berlowitz DJ, Howard ME, Fiore JF Jr, et al. Identifying who will benefit from non-invasive ventilation in amyotrophic lateral sclerosis/motor neurone disease in a clinical cohort. J Neurol Neurosurg Psychiatry. 2016;87:280-6.

16. Bede P, Oliver D, Stodart J, et al. Palliative care in amyotrophic lateral sclerosis: a review of current international guidelines and initiatives. BMJ Support Palliat Care. 2011;1:343-8.

17. Munroe CA, Sirdofsky MD, Kuru T, Anderson ED. End-of-life decision making in 42 patients with amyotrophic lateral sclerosis. Respir Care. 2007;52:996-9. 